\title{
Czech science fights against flood costs
}

[PRAGUE] Czech scientists are waiting nervously to learn what sacrifices they will be required to make to help to pay for the central European floods which covered a third of the Czech Republic in July.

The government's budget proposal is due to be presented to parliament this week. It is likely to propose cuts in funding for research which, say scientists, will make it difficult for them to bring to fruition ambitious plans to bring Czech science up to European Union (EU) standards.

Researchers are particularly worried that plans to establish what could be the Czech Republic's first international large-scale facility - a high-power iodide laser, of a type known as Asterix - could be disrupted.

Karel Jungwirth, a plasma physicist who helped to negotiate the laser's transfer from the Max Planck Institute for Quantum Optics in Germany, and vice-president of the Czech Academy of Sciences, has won promises of support from grant agencies and from special government funds (see box).

But he fears that next year's science budget may throw the timetable into disarray. "It needs to be up and running quickly so we don't lose the circle of users," he says. "But more significantly, it will be an important signal to the young that science has a future in the Czech Republic."

This is a major issue for the Czech scientific establishment, as well as the government. The sudden arrival of capitalism has seen the brightest young scientists and students turn their backs on research careers, and the average age of researchers in the Czech Republic is rising alarmingly.

Wages are particularly unattractive to young researchers. The average academic salary of 10,000 Koruna (US\$315) per month is significantly lower than the average commercial salary, and all university contracts, even those of professors, are temporary.

Scientists are campaigning hard for the government to stick to a 1996 election pledge to give science top priority after defence. But

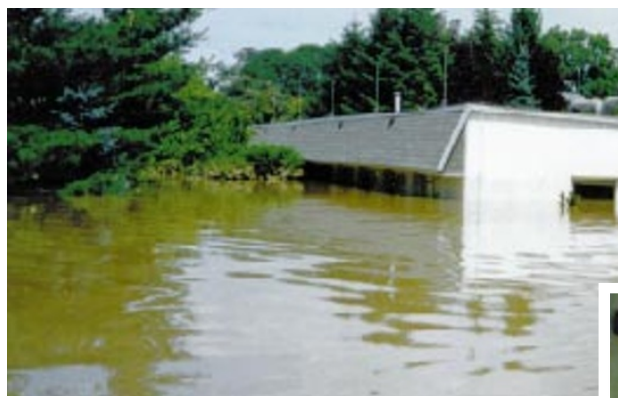

Troubling waters: science was hit directly as well as indirectly by the flooding in July. The Czech Academy of Sciences' Institute of Experimental Botany (pictured) in Olomouc, east of Prague, was under 2.5 metres of water for more than two hours. All its equipment, most of which was bought in the last two years, was destroyed.

the government, which is trying to steer the country towards membership of the North Atlantic Treaty Organization and the EU, has already shown itself unable to provide financial backing for its good intentions.

In April, the government approved its 'Principles in the field of research and development, 1997'. This promises a reorganization of research to bring it into line with EU norms. The principles pledge an increase in total state investment in research from 0.4 to 0.7 per cent of gross national product by the year of entry into the EU, which it hopes to join within seven or eight years. There are also promises to improve cooperation between academic research and industry, and to increase investment in industrial research.

Only in the past two years has the Czech Republic begun to invest significant funds in applied research, but these still total less than 15 per cent of the total state research budget.

The principles promise to continue development of initiatives already under way. These include more programmes for targeted research, promotion of university research which had been largely confined to the Academy of Sciences research institutes during the 40 years of Communism, and

\section{Academy focuses on bringing laser into use} sold to the Czech Academy of Sciences last spring by the Max Planck Institute for Quantum Optics in Garching, of DM1 (US\$0.56). It was one of a series of Asterix lasers developed in Garching and optimized for laser and $\mathrm{X}$-ray plasma experiments. It had additional support from the European Commission, and
[PRAGUE] The iodide laser was near Munich, for a token cost was used by scientists from many countries.

If financing is maintained the laser is to be housed in an academy campus on the outskirts of Prague and run by the academy's institutes of physics and plasma physics, which are also on the campus. The Max Planck Institute decided to get rid of the laser after reorienting its research plans. Under its contract with Prague, its scientists will continue to have free access to the laser when in operation.

The Czech academy hopes to maintain the laser's status as an international facility through domestic and foreign support. But it knows that if there is too long a delay in getting the laser operational, its circle of users will be lost.

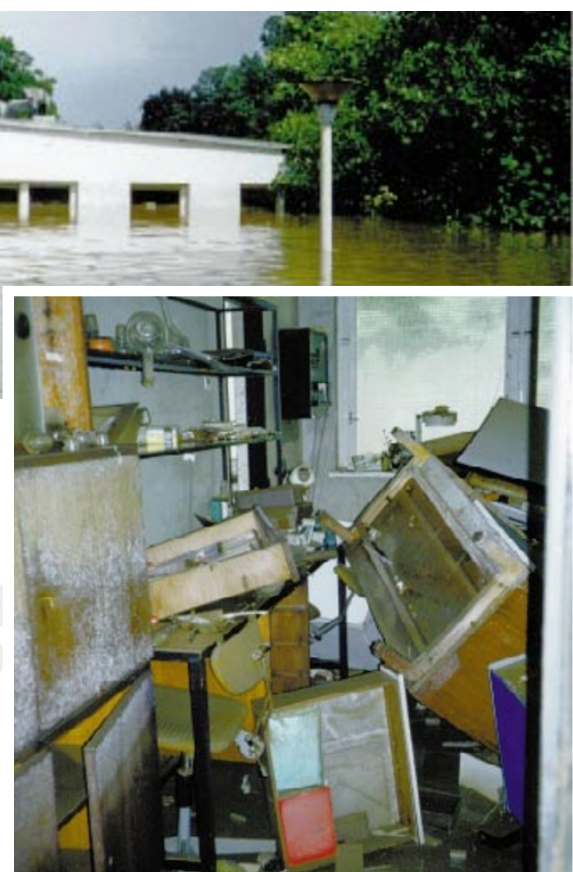

transfer of more institutional funding to grant agencies.

But, within two weeks of approving these principles, the government was forced by an economic collapse following a run on the Czech currency to introduce an emergency budget. This was followed a few weeks later by a second emergency budget.

As a consequence, the Academy of Sciences saw its budget, which had this year received its first real-terms increase since the fall of Communism, suddenly slashed by more than 10 per cent. Universities and grant agencies suffered similar cuts. Potentially most damaging was the government's decision to freeze salaries for all public appointments, including academics.

The academy feels that it has already trimmed all its fat, having closed 22 research institutes and shed more than half its staff following the halving of its budget in 1993 (see Nature 368, 386; 1994). Teams of experts, nearly half of them foreign, have completed detailed evaluations of the academy's remaining 59 institutes, and their recommendations are being incorporated into the institutes' plans. "This system is unique in eastern Europe," says Ladislav Pivec, secretary of the academy's appraisal committee.

There could be worse cuts to come. "The floods came," says Jungwirth despairingly, "and we don't know how we will cope with what this could do to our budget."

Josef Syka, vice-chairman of the government's Research and Development Council, suggests that the government will propose to maintain the total science budget at Kc7 billion, the level the current budget reached after the two emergency budgets cut it by nearly 15 per cent.

Alison Abbott 